\title{
8. The transformation of input into output: at the Melbourne Data Processing Centre
}

\section{Frances Morphy}

\section{Introduction}

I made several visits between November 2006 and March 2007 to the Data Processing Centre (DPC) in Melbourne, to observe the work of the Indigenous Processing Team (IPT). The creation of the IPT was an innovation for the 2006 Census, with a cohort of data-coders trained to deal specifically with the Interviewer Household Form (IHF). All Collection Districts (CDs) of Types 11, 12 and 13-all those consisting of or containing discrete Indigenous communities - went through the IPT. Since CDs of Types 11 and 13 also contained other kinds of communities that were enumerated via the mainstream form, the IPT coders had to deal with both kinds of forms.

I observed aspects of most stages of the data processing, from the grooming of the forms and the compilation of the Census Record Books (CRBs) before the electronic capturing of the data to coding of the first and second-release data. ${ }^{1}$ I also attended the IPT coders' training sessions on the processing of household and family data, and of data relating to occupations and qualifications. I was given the opportunity to meet with individuals responsible for instituting and overseeing general systems and procedures within the DPC, and this helped me to gain an overview of the Indigenous Enumeration Strategy (IES) coding within the broader context of DPC activities.

As a field site, the DPC was very different from the remote area where I observed the enumeration and from the Darwin Census Management Unit (CMU). During the enumeration, I had been working in an environment that I knew well and where I had undertaken a similar exercise in 2001 - and, as a result, I had an overview of the process that was informed by my prior local knowledge. Also, since the filling in of the IHF was a protracted exercise, it was possible to make very detailed observations of the initial data collection, in 'real time' as it were. At the $\mathrm{CMU}$, although the institutional environment was initially unfamiliar, I was observing a relatively small-scale operation - in contrast with the DPC - and one in which, although use of information technology was a significant component, face-to-face interactions - for example, in the training sessions - and

1 For the mainstream count, the CRBs were compiled in the field and the DPC had to reconcile discrepancies between the counts on the form and those in the CRBs. For the IHF forms, however, the compilation of the CRBs took place at the DPC. 
manual processing of the IHFs (with people talking about what they were doing as they worked) were important elements of the process. The data were also arriving at a pace and in a form in which I could 'capture' it for the purposes of my own analysis.

In contrast, the DPC is a very large and complex-and highly technologised - environment. I had to rely largely on others for the information that would allow me to understand its workings, rather than observing for myself. Although I was able to observe the training of the data-coders in a manner similar to my observation of the training of the Census Field Officers (CFOs), once they started work the situation was very different. Whereas in the field and at the CMU the data were always in context - physically on a form that was in a box with other forms from the same place - once the data from the forms had been captured electronically at the DPC it was dissociated from those contexts. Although the coders could call up the electronic copy of the form if need be, for the most part they were working, at high speed, on snippets of information divorced from the wider context of the forms. In order to meet processing deadlines, they had to concentrate hard and work fast. There were fewer contexts for me to observe people's own commentary on what they were doing, and - with one exception, which I will note below- the data were not 'capturable' in the same way as in the earlier contexts.

In my work at the DPC, I was concerned less with analysing the organisational aspects of the exercise than was the case in the field, although I will make some brief general comments based on my rather superficial knowledge of what was a very complex and technologically sophisticated operation. My primary aim was to follow the progress of my own case-study IHFs, so I would have a complete picture of the journey of the data through various contextual frames, from its elicitation during the count to the coded end product.

There was not much more to observe as far as the basic 'head count' aspect of the census was concerned. The IES team did run another check on the internal consistency of the records while compiling the CRBs during 'pre-capture'. They also checked whether people who had been moved from 'persons temporarily absent' (PTA) status to 'inside the form' had then been eliminated from the PTA list at Question 11. By and large, this was not a problem with the Northern Territory forms - thanks to the work of the Darwin CMU— but quite a few 'duplicate' people were found in the IHFs from other States. In such cases, the person was usually retained inside the form at Question 12 and eliminated from the PTA list unless it was clear that they would have been counted elsewhere, for example, at boarding school. There were a few cases where the sex of individuals was missing, and these were imputed. ${ }^{2}$

\footnotetext{
${ }^{2}$ In some cases, ages were missing. These were imputed at a later stage during system edits.
} 
I was most interested in the coding of the data that had as yet received little attention at any stage of the checking process in the field or at the CMU: this was the primarily socio-demographic information-household and family composition, language use, education, employment and so on. Many of the questions on the form relating to these issues required a written answer and, for the IHF, answers to such questions were coded manually. This was a major difference between the coding procedures for the standard form and the IHF. ${ }^{3}$

I was interested in the categorisations that underlie the coding process and how the data were fitted to those categories. As I have argued elsewhere (Morphy 2007), the categories in terms of which the national census is framed are derived from the culture of the mainstream and reflect the concerns of the nation-state. In Villaveces-Izquierdo's (2004: 178) words: '[T] he census is a tool through which the state envisions and acts upon the nation.' These categorisations, which also underlie the framing of the questions on the form, are opaque to those who fill in the forms - the collector-interviewers (CIs) and the interviewees. ${ }^{4}$ In many cases therefore, the answers given to questions - particularly where written answers are required rather than simply the ticking of a box - are often difficult to interpret in terms of the preset coding categories. This was the main reason why such responses were coded manually.

In the field, I had been interested in the categories that Yolngu brought to bear in responding to the census questions, and what kinds of answers this produced. At the DPC, I was interested in how their answers were interpreted and slotted into the coding categories. I was interested in the demographic portrait of the Yolngu population that was produced as the end result of this process, and the degree to which it was commensurable with: a) the Yolngu view of themselves, and b) a depiction informed by anthropologically derived categories.

Some might argue that this is an unnecessary and even misconceived exercise, that the purpose of the census is, precisely, to gather demographic 'facts' that are comparable between different sectors of the population. My argument will be that, to the degree that these 'facts' are socio-demographic rather than socially neutral, they will be categorised differently depending on the cultural lens through which they are viewed. Census categories are not culturally neutral, and it cannot be assumed a priori that the categories of one socio-cultural system are translatable directly into those of another. To some extent, then, this chapter

\footnotetext{
3 In mainstream processing and for some of the questions on the IHF, responses are coded automatically by the system. If a code cannot be determined automatically then manual intervention via an online coding system takes place. For the IHF forms, automatic coding (AC) is switched off for the majority of topics.

4 This is true to some degree of all people who fill in a census form - with the exception of a small expert group of population specialists, including those employed by the ABS - but, in the case of people whose cultural categories diverge significantly from those of the mainstream, that opaqueness is compounded.
} 
is less a commentary on my observations of the operation of the DPC and a more broad-ranging commentary on the nature of census data and its limitations.

\section{The Indigenous Processing Team: a brief appraisal}

Since I was not present at the DPC for the 2001 Census, I am not in a position to compare the functioning of that DPC with the 2006 DPC. It is possible, however, to assess whether the procedures put in place had strengths and weaknesses in their own right. My overwhelming impression - from my own observations and from conversations with IPT and other DPC staff-was that the IPT was a worthwhile innovation and that it should be retained for future censuses. It is needed for the same reason that the IES itself is needed-the 'difference' of Indigenous people in remote areas of Australia-and indeed it should be considered from now on as part and parcel of the IES.

It was found in 2001 that automatic coding (AC) was not successful in coding certain questions on the Indigenous forms, and for certain questions (as noted above) AC was switched off and the IPT coders were instructed to code manually. In this situation, there are advantages to the DPC in having to train only a small number of coders to work with the IHF, and having a small cohort allows for efficient quality assessment and feedback to the coders.

The IPT followed a policy of attempting to make minimal use of the option 'Not adequately described', and this meant the coders had sometimes to be quite lateral thinking in their coding solutions. In order to maintain consistency across coders, it was necessary to give feedback constantly to individuals and the group, and to monitor for patterns in the solutions adopted, particularly for less adequate solutions. When such patterns were noted, ad hoc tutorials were held to help the coders achieve better and more consistent solutions. All this would have been much more difficult to maintain rigorously with a larger number of coders.

The other major advantage of a specialist unit is that it can serve as a repository of specialist knowledge. A great deal of background research had been done to assist the coders in such matters as identifying the Indigenous languages that appeared on the forms and in compiling exhaustive lists of community names with their variants, and the family coding and the coding for occupation and qualifications required extra knowledge over and above what was required for the mainstream forms. Again, it is more efficient to train, monitor and assist a relatively small number of specialist coders rather than attempting a more general exercise involving all coders.

In assisting the coders to do their work, the DPC has to maintain a delicate balance. It must provide them with enough information to code accurately and quickly, while avoiding the pitfall of providing information that might bias them towards particular interpretations of the data. It is a cast-iron rule of coding 
that the coder must work with whatever information they have-and only that information - and this rule is in creative tension with the imperative to avoid coding a response as 'not adequately described' wherever possible.

The additional sources of information that were available to IPT coders included the community forms from the Discrete Indigenous Community Database (DICD) and the $\mathrm{CFO}$ and $\mathrm{CMU}$ checklists described in the previous chapter. They had access also - on request to the data-analyst on the floor - to extensive materials on Indigenous languages and on localities. These last two were invaluable and, for the Northern Territory at least, the CMU and CFO checklists often provided useful additional information, such as how the PTAs for a particular CD had been treated. The DICD forms were less useful, except as a check on the number of people and dwellings in a CD. As noted in earlier chapters, the CFOs had not, by and large, completed these in any great detail. Coders were encouraged to add to the forms, for example, by recording variant spellings of language names that appeared on the forms. If these forms are attended to and updated during the inter-censual period, they will potentially be an invaluable resource for the coders in 2011. This database is to be maintained by the National Centre for Aboriginal and Torres Strait Islander Statistics (NCATSIS), and we have suggested in Chapter 9 that the updating should be the responsibility of Indigenous Liaison Units - rather than a solitary State Indigenous Manager-located in the State and Territory offices.

Another procedure followed by the IPT that differed from the mainstream processing was to base processing on CDs. In the mainstream processing, coding was topic based, with different teams of coders working on different topics rather than on whole forms. The IPT procedures allowed the coders to become familiar with patterns of naming and other reoccurring information for particular communities, leading to more consistency in coding. From my observations, this generally worked very well. For example, once a coder became familiar with all the language names for a particular community, this speeded up the coding process considerably. It also helped the team managers in their quality-assessment work, since if a coder made a particular error it was likely to be repeated for the whole CD, showing up as a clear pattern.

In order to allow for flexibility in coding when faced with variety in the written responses to questions, the coders worked with colour-coded 'pick lists'. Some choices had to be exact matches, others allowed for close or approximate matches. As a last resort, the coder could choose to bypass the pick lists and go into a 'best-fit' process. In best fit, the coder was required to state their reason for choosing that path and this will presumably allow the ABS data-analysts to refine the pick lists for 2011. This seems to me to be a good idea, because it allows the coders some latitude with aberrant answers, and also allows them to signal 'gaps' in the options offered. It is unclear to me, however, how the 
subtleties of these procedures will be translated into the output data. I noted that coders differed in their propensity to opt for going into best fit. Some tried several pathways within the pick-list system and went to best fit only as a last resort, while others were quicker to opt for the best-fit solution.

\section{Some global problems}

The lists of localities for the coding of workplace addresses were provided by the State Transit Authorities (STAs), and were much less comprehensive than the ABS's own locality lists used in other questions. This was the case particularly for remote areas of the country - the majority of discrete Indigenous communities seemed to be missing. ${ }^{5}$ This threatened to force the coders into a lengthy and tortuous coding process. They were essentially instructed to bypass the process and code the State, followed by 'Community further investigation'. It is hoped that these STA lists will be more comprehensive for 2011.

In family-coding mode, the coder had access to all the forms relating to a household - in instances where there was more than one form because there were more than 12 people in the household. This was not the case, however, when coding some other questions, such as the language question, and this caused problems if the answer was 'Same as Person 1'. If this answer appeared on the second or a subsequent form for the household, the coder no longer had easy access to the answer given for Person 1, on the first form. There seems no good reason why the system should not allow for the first form to be readily accessible for all coding.

In Chapter 7, I noted that at the Darwin CMU the answer to Question 15 ('Where does this person live most of the time?') was checked carefully for each individual. If this question had been left blank, and it was obvious from the answer to Question 12 that the individual was not a visitor, the 'This community' box was marked. It transpired that this was a very important exercise, since according to the coding conventions at the DPC the answer to Question 15 overrode the answer to Question 12. If the 'This community' box was left unchecked at Question 15, the individual could not be included in the family coding for the household even if they had replied, at Question 12, that they were not a visitor. This was one of several examples that I noted at various points in the process from data collection to data processing where a very small detail could have very large consequences. Thanks to the Darwin CMU, this will not have been a problem for the Northern Territory, but I do not know what happened in other CMUs.

5 Given all the work that the IPT had put into compiling a comprehensive list of community names, this was irritating, to say the least. 
There were other glitches in the system that required ad hoc coding solutions, but it seemed to me that these were dealt with efficiently through the impromptu tutorial sessions and the more formal training sessions.

\section{Family coding: what is being coded, and why?}

At the beginning of the training session on IHF family-coding procedures, the coders were reintroduced to the concept of the 'statistical family' that had been explained to them in the training for mainstream family coding. They were reminded: 'Statistical families are governed by a strict set of coding rules that conform to international standards. Often these statistical families do not reflect the true status of family members as seen by other family members and their community.'

They were told also that this 'applies even more' to some Indigenous households. The definition of the statistical family is: 'Two or more persons, one of whom is at least 15 years of age, who are related by blood, marriage (registered or de facto), adoption, step or fostering, and who are usually resident in the same household.'

Indigenous households pose particular problems for coding according to this definition, for several reasons. The ABS allows for only three statistical families in any household, and it allows for only three generations in a family. If there are more families, or more generations, additional families have to be merged with the 'primary' family in the household. In some cases, individuals who are closely related to someone in a household are classified simply as 'other relative' to the 'head' of the primary family once this process has dismantled their own family. It was interesting that the trainers anticipated that coders would find this unsettling - they were told to be 'unemotional' about following this procedure.

Other stray comments alerted me to the emotions that family-coding procedures could engender - in stark contrast with coding for occupation and qualifications, which were equally subject to a set of formal definitions and procedures. One visitor from the Darwin CMU advised a colleague, also visiting from Darwin, not to watch what was being done in family coding because of what it did to the data, and one of the coders who had lived in a discrete Aboriginal community also commented to me in passing how aware she was that family coding did not capture 'what is really out there'. It seems at first glance that matters to do with family strike an emotional chord that is at odds with a 'statistical' approach; it seems to make people uneasy to see relationships being objectified in this way. That is not the whole story. People would probably feel less ambivalent if they felt that what was being captured was somewhat closer to what is 'really out there'. 
About halfway through the family-coding procedures, at a feedback session on the floor, the coders discussed difficulties they were having with family coding. They mentioned the three-generation and the three-family rules as problematic. One person also thought part of the problem was having to relate everyone to a single person, and suggested a matrix approach, in which everyone in the household was related to everyone else.

In my view, this last suggestion would be unworkable, given the size of many Indigenous households. For example, with a household of 20 people, according to my calculations, 190 different kinship dyads would have to be recorded. Even with a household of 10, 45 different kinship dyads would result. The chances of recording, in every case, the 'correct' Anglo-Celtic relationship would approach zero. The result would be more incoherent data, on a grander scale, and a coder's nightmare. There is little point in asking for further relationship details for other relatives, since the data that result have a good chance of being incoherent and misleading (see Morphy 2004, 2006). I have written in detail elsewhere (Morphy 2004, 2006, 2007) about the inherent difficulties of translating between incommensurable kinship systems and I will not repeat that discussion here. Nothing of what I observed in 2006 has, however, persuaded me against the recommendation that I made as a result of observing the count in 2001: that, for coding purposes, a new type of household should be added to the ABS list of definitions - the 'extended family household'. This type of household could potentially be useful for capturing information about more than just Indigenous households.

The default assumption, if evidence is missing or conflicting, would be that everyone in such a household is related to everyone else. Only where a person is stated explicitly to be something else - for example, a 'friend' - would they be classified as unrelated. In the 2006 Census, the large number of PTA who were moved back inside the form - at least in the Northern Territory - had to be classified as unrelated because there was no information on their relationships to other members of their households, whereas in fact it is much more probable that they were related to other members of the household (invariably so in the cases that I observed). In 2006, the large numbers of PTAs with no relationship data who were put back into the forms will generate a lot of spurious 'unrelatedness' in Indigenous households.

The sub-units within these households should not be called 'families'; they are, rather, sub-units of the extended family, and should be distinguished terminologically as conjugal units - with or without children - or single parent-child units. The terms 'couple family' and 'lone-parent family' should be reserved for households consisting of such unit types, and applied to them only. 
I also see no useful purpose in maintaining the arbitrary cap on the number of such units that occur in a household. Nor do I see any useful purpose in assigning members of the grandparental generation arbitrarily to one unit or another, when they are equally closely related to members of several units. If this convention is abandoned, the necessity for the arbitrary cap on the number of generations within a 'family' also disappears.

Questions 31 and 32 (see Appendix A) should stay for 2011 as a means of identifying the sub-units within the extended family household. The collectors just need to be trained to implement them better. There is more chance of a 'match' between Anglo-Celtic and Indigenous systems when dealing with very close core kin. Indigenous CIs can in general cope with translation between Indigenous terms and the Anglo-Celtic terms 'father', 'mother', 'son' and 'daughter'.

During family coding, the coders were asked to document on paper the solutions they reached for the more complex households. This was invaluable for me in my analysis of what happens in the translation process. In my opinion, however, they would be of limited use as a basis for attempting a new classification of the internal structure of Indigenous households. They do not record what is really 'out there'. They are not neutral representations of Indigenous family structures, but artefacts of the current coding system (see Morphy 2007). ${ }^{6}$

In conclusion to this section, I pose the same question that I posed in 2001: what is family coding for? In their training, the coders were told that 'we do not try to capture relationships in terms of carers and finances'. Perhaps this is precisely what the census should be trying to capture and compare across different sections of the population. In socioeconomic terms, the family-however it is constituted - is the bedrock institution of any society, the site where children are raised, supported and socialised, and where those not in the workforce are supported by those who are. Family policy is almost invariably directed to these aspects of the family as a social institution. The question of precisely which categories of kin do or do not live in the same household is - or should be - a secondary consideration at most. The terms 'couple family' and 'lone-parent family' carry with them cultural assumptions about the nature of such families that cannot be projected simply from one cultural setting to another. For example, the child of a single mother who is living in an extended family household - where other adults besides the mother play a large part in their care - is in a very different situation to a child whose mother lives without such a supportive kin-based network.

6 These family trees will be shredded when the DPC winds up, so cannot be used in this way in any case. 


\section{Occupation: CDEP and the invisible economy}

Very wisely, the DPC had instituted a dedicated 'pick list' for Community Development Employment Project (CDEP) occupations. ${ }^{7}$ The majority of 'employed' Indigenous people in remote Australia are CDEP participants (see, for example, Gray and Chapman 2006: 117). The instructions to the coders were to use this pick list as the first port of call whenever CDEP was mentioned, no matter which of the employment-related questions it appeared in. They were also warned that some people who worked for CDEP organisations were not CDEP participants, and to exit the CDEP pick list into the mainstream occupation coding options when a person's job description evidently did not fit within the CDEP listings. There was a concern that sometimes the level of CDEP-related jobs might be understated. For example, if someone said that they were a 'receptionist', this should not be automatically coded to 'administration or clerical work' on the CDEP pick list.

The CDEP pick list was compiled using responses from the 2001 Census, and this might have been an adequate strategy were it not for the case that CDEP was undergoing rapid and radical change at the time of the 2006 Census (DEWR 2005a, 2005b, 2006). The process of refocusing CDEP towards training people for 'real jobs' was encouraging the relabelling of 'traditional' CDEP jobs. Women who had previously been receiving their CDEP for 'home management' or 'home duties' were now working in 'environmental services' or 'community care', for example, as were many former 'rubbish collectors'. These changes to CDEP were very recent at the time of the census, and in Arnhem Land I had observed some people still using the older categories. By the time of the next census, if CDEP is still in existence, I would expect most CDEP participants to be more aware of their 'official' job descriptions, since each CDEP participant is now given a written formal job description and training plan. It would be advisable then to construct the CDEP pick list primarily from the Department of Employment and Workplace Relations' (DEWR) list of job descriptions in 2011, possibly supplemented by information from the 2006 responses.

The increasingly significant role of the Indigenous Protected Area (IPA) scheme and associated ranger programs was evident in the responses to CDEP questions. The closest equivalent in the CDEP pick list was 'park ranger'. It was decided to best fit 'community ranger' - the most common description of ranger jobs associated with IPAs - to 'park ranger' rather than simply picking it from the list, as a way of alerting the data-analysts to the gap in the pick list. By 2011, depending on the continuing success of the IPA program and the ability of these ranger programs to attract funding, many of these ranger positions could be non-CDEP jobs.

\footnotetext{
7 The special CDEP coding was used only for IHF forms from remote communities, and not for coding the occupations of Indigenous people enumerated on mainstream forms.
} 
The instruction to use CDEP as the entry to job classification wherever it appeared in the answers to work-related questions was a relaxation of normal coding procedures-but a sensible one. In general, respondents are not able to discriminate very clearly between questions that ask for a distinction between a job description and the list of tasks performed, nor are they able, in many cases, to provide a coherent or accurate description of what their 'employer' does. The questions on the census form are designed with mainstream employment situations in mind, and do not have salience for people who are not employed in the mainstream. Had the coders been faced with attempting to code CDEP responses as if they were mainstream responses, their task would have been much more arduous and frustrating.

As in 2001, I was struck forcibly by the silences - the gaps in information - that the form of the census questions on economic participation engendered. The overwhelming impression of remote Indigenous Australia is of economically marginalised people, in low-paid, part-time, low-skilled, 'dead-end' occupations. The biggest silences concern the subsistence economy and participation in the art industry. Some commentators (Hughes 2007; Johns 2006) dismiss subsistence hunting and gathering as merely recreational, whereas in many areas of remote Australia - particularly in outstation communities - there is evidence that these activities contribute significantly to the health and wellbeing of the population (see, for example, ABC News Online 2006; Barber 2005; McDermott et al. 1998; Morice 1976; Watson 2007). There is, however, nowhere on a census form where people are encouraged to record these activities - not even in the question on unpaid domestic work. Perhaps for the next census that question could be reworded to make it less 'feminine' and 'hunting, fishing or gathering bush food' could be included among the suggested options.

The Indigenous arts industry is a major component of the remote economy (see, for example, Altman 2003). The study area where I observed the enumeration in 2006 contained one extremely successful art centre, many successful and well-known artists and many others who were learning from the more established artists. Despite the inclusion of 'artist' in the list of suggestions for occupations, however, only one or two people put this down as their occupation. It is clear that the majority of people do not really think of art production as a job, and the emphasis in the census questions on sources of regular income - as opposed to intermittent and somewhat unpredictable income - conspires with this attitude to render an important source of income and economic engagement essentially invisible.

From the Yolngu point of view therefore, art production is not a 'job', even if it is a source of income. There are, however, some things considered by Yolngu to be 'jobs' that the mainstream categories ignore. Several senior Yolngu who were CDEP participants described their occupation as 'leader' or 'community 
leader'. Needless to say, there was no match for these in the CDEP pick list, and it is very unlikely that such are their 'official' CDEP job descriptions. It proved very difficult to deal with such cases even in 'best fit' or by exiting the CDEP module, since equivalent jobs in the mainstream generally imply high levels of formal (Western) education and qualifications, and incomes to match. From the point of view of these senior Yolngu, however, this is indeed their most important job, and it can be demanding and time-consuming.

It is extremely interesting to see these cultural differences in the idea of what is and is not 'work' being played out through the census process. What is frustrating is that none of this complexity is evident in the official output of the census - the tables representing the 'facts and figures' of Indigenous employment. Arguably, however, if effective measures are to be put in place to improve the economic circumstances of Indigenous people, it is as necessary to understand differences in perceptions and values as it is to understand the 'facts' as they appear through the lens of the mainstream.

\section{Conclusion: the representation of Indigenous Australians in the census}

In considering this question in the context of the DPC, the most obvious point to be made is: coders can code only what is there in the forms. No matter how advanced and sophisticated the technology, no matter how expert, well-trained and dedicated the staff, no matter how effective the systems for checking internal consistency, the fact remains that one gets out what one puts in. And what is put in is a very partial representation of the Indigenous 'facts', couched in the categories of the mainstream. It was somewhat disconcerting to see such care, thought, expertise and expense being devoted to the processing of this data - in particular, the household data.

The data are partial in at least two senses. Firstly, because of the intercultural difficulties of the enumeration exercise, many data are missed, or presented incoherently. The forms are filled in incompletely or the answers are hard to interpret. Secondly, the data are partial in the sense that it captures only a partial representation of Indigenous lives and circumstances. Some would argue that this is necessary and desirable - the state needs to know only so much about its citizens in order to plan and deliver policy and services. What is more, the census is a broad-brush instrument. It is not designed to capture the subtleties of social life. There are, however, unhelpful cultural biases in this partiality that could be addressed, so that a more accurate partial picture emerges - one that would make Indigenous people more recognisable to themselves in the output of the census. To that end, I have gone into some detail on the subject of the representation of the family structures of Indigenous households. 